\title{
Maternal Toxicity and Ultrastructural Changes of Copper 0xy- Chloride in Pregnant Female Albino Rats
}

\author{
Elalfy MM1*, Abd Allah $\mathrm{AA}^{2}$, Mahmoud $\mathrm{HA}^{3}$, Abomosallam $\mathbf{M}^{1}$, \\ Hamed $\mathrm{MF}^{4}$ and Sleem $\mathrm{F}^{1}$ \\ ${ }^{1}$ Department of Forensic Medicine and Toxicology, Mansoura University, Egypt \\ ${ }^{2}$ Agriculture Research Center, Egypt \\ ${ }^{3}$ Department of Pesticide Residues and Environmental Pollution, Egypt \\ ${ }^{4}$ Department of Pathology, Egypt
}

Research article

Volume 2 Issue 3

Received Date: June 19, 2019

Published Date: June 28, 2019

DOI: $10.23880 /$ izab-16000159

*Corresponding author: Mahmoud Elalfy, Mansoura University, Forensic medicine and toxicology faculty of veterinary Medicine, 35516 Egypt 60-Elgomhouria St, Mansoura City, Egypt, Email: dr_melalfym@mans.edu.eg

\section{Abstract}

The excess application of COC may have an adverse effect on both animals and human population to better understand the maternal toxicity estimated in pregnant female albino rats, COC administered orally at different doses $(1 / 10$ and $1 / 20$ $\mathrm{LD}_{50}$ of COC equivalent to $147 \mathrm{mg} / \mathrm{kg}$ bow and $73.5 \mathrm{mg} / \mathrm{kg}$ Bw. respectively) daily from day $6^{\text {th }}$ to day $15^{\text {th }}$ of pregnancy with daily observation and weighing. The pregnant dams were sacrificed on day $20^{\text {th }}$ of gestation and blood and tissue samples collected for hematological, biochemical, histopathological, ultrastructural changes examination besides copper residues level determination in the liver tissues. The results showed that there was a significant dose-dependent decrease in the maternal body weight with respect to the control group besides a significant decrease in the metabolic parameters as glucose, total protein, and cholesterol however, there was a significant increase in the liver enzymes, urea and creatinine furthermore there was a severe decrease in the antioxidant biomarkers as SOD, CT, GSH and GST with a significant increase in the level of MDA revealing oxidative stress additionally the results found that the was a sever histopathological and ultrastructural changes in the liver tissue and hepatocytes. Furthermore, the level of copper in the liver tissue increased significantly in treated dams in comparison to control. Such results revealed the potential maternal toxicity of $\mathrm{COC}$ fungicide in a dose-dependent manner in female albino rats after the accumulation of copper in the liver tissue that considered as the main target organ.

Keywords: Copper Oxychloride; Greenhouse Fungicide; Maternal Toxicity; Coper Residues; Ultrastructural Changes; Female Albino Rats

Abbreviations: Hb: Hemoglobin; RBC: Red Blood Cell Count, HCT: Hematocrit: MCV: Mean Corpuscular Volume, MCHC: Mean Corpuscular Hemoglobin Concentration;
MCH: Mean Corpuscular Hemoglobin; UPD: Up and Down Procedure; PBS: Phosphate Puffer. 


\section{International Journal of Zoology and Animal Biology}

\section{Introduction}

Fungicides are chemicals that used for eradication of fungi and classified as Fungi statics that prevent fungi development or antisporulants that prevent of reproductive spore formation [1]. Copper compounds as soluble copper salts act on the fungal metabolism whereas the presence of high quantity metallic ions causes various disturbances and has a toxic effect in the fungal cells causing coagulation of the cellular protoplasm, denaturation of the cellular membrane, depression of the respiratory processes and also act as anti-metabolites [1]. Copper containing pesticides have a significant historical value due to its fungicidal properties, although copper is relatively safe, there is a great concern due to its accumulation in the agricultural soils through heavy and improper application [2]. Copper based fungicide may accumulate in various tissues as a heavy metal causing hepatocellular neoplasia, kidney dysfunction and hemolytic anemia [3].

Copper oxychloride fungicide act on fungal diseases of fruits and vegetables to be edible for consumption and improve their productivity [4]. Copper oxychloride is widely used in several applications per season in rate of 1.25 to $7.5 \mathrm{~kg}$ / ha but it not only affects fungi but also non target organisms and may be lethal upon several applications with inability of tissues to synthesize copper binding ligands $[5,6]$.

Toxicity of copper oxychloride was higher than that of organic pesticide as the metal concentration might have a significant effect on the toxicity degree of pesticides and with higher metal content the toxicity became stronger [7]. Liver (the target organ in copper oxychloride toxicity) showed a sever pathological lesions, degenerations and swollen nuclei and mitochondria besides increase in levels of transaminases and ammonia, also copper oxychloride induced metabolic, hematological and behavioral impairment with increase in glucose level with significant decrease in leucocyte count due to immunosuppression [8]. Copper oxychloride in a toxicity study in rats showed a sever decrease in the food consumption and the whole Hematological parameters as hemoglobin, $\mathrm{MCH}$ and red blood cell count in a dose dependent manner on the other hand there was a sever increase in the white blood cell and the oxidative damage proteins and lipids [9]. Exposure of rats to $\mathrm{COC}$ in a toxicological study showed that COC may harm human and public health causing hepatotoxicity and lipid peroxidation with a significant increase in ALT and AST liver enzymes that considered as biomarkers of hepatic injury besides a marked increase in the liver MDA due to lipid peroxidation [10]. Active transition metals accumulation as $\mathrm{Cu}$ showed a significant increase in the production of free radical that share in turn in oxidative stress and cellular damage [11].

So copper oxychloride may also oxidize cellular macromolecule as proteins, lipids and DNA through Fenton reaction resulting in hydroxyl, ROS radicals, oxidative stress causing increase in the levels of SOD, malondialdehyde and glutathione-S-transferase especially in liver tissues, on the other hand decrease in catalase activity, $\alpha$-tocopherol and glutathione peroxidase besides mitochondrial swelling depressing the cellular respiration and normal cell growth and development [12]. Copper level in COC treated rats increased significantly besides histopathological changes in the hepatic tissue as congestion with inflammatory cells and hepatic degeneration also COC induced caspase 3 inhibition with necrosis in the liver tissue [10]. Copper oxychloride toxicity and hepatocellular injuries was studied with the electron microscope in rats and revealed that accumulation of copper in nucleus and nuclear irreversible damage so nuclear degeneration considered as the initiating event in hepatic toxicity in the whole liver that considered as the primary target organ in copper toxicity also revealed that the lysosomes not responsible for the cytotoxic effect on copper as previously thought [13]. In a cytotoxicity study on HepG2 and HaCaT cell lines copper oxychloride showed a significant cytotoxic effect on skin as well as liver after exposure to 20-450 $\mu \mathrm{g} / \mathrm{ml}$ for 24 so continuous exposures to this fungicide is harmful to human and animals health [14].

The rationale of this study to explore the maternal toxicity of fungicide copper oxychloride tat used extensively as fungicide in green house in our area.

\section{Material and Methods}

Fungicide: ACROBAT CU 73.2\% WP (copper oxychloride) or (COC):

Light green wettable powder (WP) with slight chlorine odor and kindly obtained from Central Agricultural Pesticide Laboratory, Ad Doki, Giza, Giza Governorate (Figure 1)

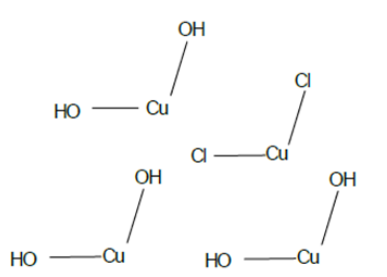

Figure 1: Fungicide. 


\section{International Journal of Zoology and Animal Biology}

\section{Laboratory Animals}

24 Mature female's albino rats obtained from Experimental Unit in the Faculty of Pharmacy, Mansoura University; Animals weighed about $250 \pm 10$ gm and were obviously healthy then grouped and housed in plastic cages with soft wood shavings as a bedding material that changed adequately to ensures a low level of ammonia and to keep animals clean and dry.

Animals adapted for about 2 weeks and maintained on a balanced ration before the experiment also standard laboratory pelleted diet and water given ad libitium throughout the experiment and Light cycles of 12 hours' light to12 hours dark seemed to be adequate in order to promote rodents' breeding.

\section{Calculation of LD50 of Cu Oxychloride}

The LD50 of COC was calculated according to the Up and Down Procedure (UDP) that proposed by Bruce, et al.
[15] and revised and modified through and accepted as a method for calculation of LD50 through AOT 425 statistical program and the estimated LD50 was nearly $1470 \mathrm{mg} / \mathrm{kg}$ [16].

\section{Experimental Design for Prenatal Maternal Toxicity Study of $\mathrm{Cu}$ Oxychloride in Pregnant Female Albino Rats}

Twenty four synchronized pregnant females were separated into three groups with eight for each whereas the duration of exposure designated to be from day $6^{\text {th }}$ to day $15^{\text {th }}$ of pregnancy daily orally by stomach tube, the first group received $0.5 \mathrm{ml}$ distilled water and used as control, the second group administered 1/10 LD50 of COC equivalent to $147 \mathrm{mg} / \mathrm{kg} \mathrm{Bw}$., the third group gavaged $1 / 20 \mathrm{LD}_{50}$ of $\mathrm{COC}$ equivalent to $73.5 \mathrm{mg} / \mathrm{kg} \mathrm{Bw}$, the pregnant females were weighed and kept under observation daily until the day $20^{\text {th }}$ of gestation (the day of sacrifice).

\begin{tabular}{|c|c|c|c|c|c|}
\hline Group & $\begin{array}{c}\text { No. of Pregnant } \\
\text { rats }\end{array}$ & Treatment & $\begin{array}{c}\text { Oral dosage mg/kg } \\
\text { B.wt }\end{array}$ & $\begin{array}{c}\text { Duration of exposure } \\
\text { during pregnancy }\end{array}$ & Sacrificing \\
\hline I & 8 & D.W & $0.5 \mathrm{ml} / \mathrm{rat}$ & $6^{\text {th }}$ to $15^{\text {th }}$ & $20^{\text {th }}$ \\
\hline II & 8 & Cu oxychloride & 147 & $6^{\text {th }}$ to $15^{\text {th }}$ & $20^{\text {th }}$ \\
\hline III & 8 & Cu oxychloride & 73.5 & $6^{\text {th }}$ to $15^{\text {th }}$ & $20^{\text {th }}$ \\
\hline
\end{tabular}

Table 1: The experimental design summery for prenatal maternal toxicity of cu oxychloride in pregnant female albino rats.

\section{Prenatal Maternal Toxicity of Dams Upon Exposure to $\mathrm{Cu}$ Oxychloride}

Clinical signs: The treated pregnant females observed daily throughout the experimental period for any abnormal behavior, findings or alteration.

Maternal body weight gain: The initial body weight determined and then throughout the experiment the body weight calculated before each administration. The body weight gain \% determined according to the following formula [17].

$$
\text { Body weight gain } \%=\frac{(\text { Final body wt }- \text { initial body weight })}{(\text { initial body weight })} \times 100
$$

Sample Collection: At day 20 of pregnancy, pregnant dams euthanized with thiopental $\mathrm{Na}(40 \mathrm{mg} / \mathrm{Kg}$ i.p).

For hematological examinations fresh blood sample collected from the heart with a sterile syringe and then collected in centrifuge tubes contain K3EDTA as anticoagulant.
For biochemical analysis fresh blood collected in gel tube (not contain anticoagulant) then left overnight in refrigerator followed by serum separation in centrifuge at $3000 \mathrm{rpm}$ for 15 minutes then stored at $-20^{\circ} \mathrm{C}$ in Eppendorf tubes.

For Oxidative stress determination, liver sample removed and washed with saline solution then one gram of tissues homogenized in falcon tube with $9 \mathrm{ml}$ ice cold phosphate puffer (PBS) PH7.4 through homogenizer then centrifuged at $3000 \mathrm{rpm}$ for about 15 minutes at $4^{\circ} \mathrm{C}$, the supernatant separated, collected and stored at $-20^{\circ} \mathrm{C}$ in Eppendorf tubes [18].

For histopathological examination liver, spleen, kidney, brain and placenta specimen collected and kept in $10 \%$ neutral buffered formalin.

Hematological Examination: Blood sample analysis carried out by Mindray BC- 1800 hematological analyzer whereas hemoglobin ( $\mathrm{Hb})$, red blood cell count (RBC), hematocrit (HCT), mean corpuscular volume (MCV), mean corpuscular hemoglobin concentration (MCHC) and mean corpuscular hemoglobin ( $\mathrm{MCH})$ evaluated besides total 
and differential white blood cells were also measured [19].

\section{Biochemical Analysis}

a) Metabolic, kidney and liver function biomarkers: sera of all rats were tested for GGT activity, ALT activity, Glucose, total protein, albumin, creatinine to, urea and cholesterol [20-27].

b) Antioxidant and oxidative stress biochemical analysis: Liver homogenate were analyzed for GSH, GST, SOD, CAT and MDA [28-31].

Histopathologic examination: Specimens from liver, kidney, spleen and brain were fixed in $10 \%$ formalin and $5 \mu$ thickness sections of specimens prepared then stained with hematoxylin and eosin (H\&E) and examined microscopically [32].

Transmission Electron microscope examination: Liver samples with $1 \times 2 \mathrm{~mm}$ thickness were taken and Fixed in 5 $\%$ glutaraldehyde solution immediately after animal dissection for $24-48 \mathrm{~h}$. Then specimens washed in cacodyl ate buffer (PH 7.2) for 4 times and for 20 minutes each time followed by fixation in $1 \%$ 04S4 for 2 hours then washed in the same buffer for four times again . Dehydration then applied in ascending manner with different alcohol concentrations (30 - 50 - 70 - 90 and $100 \%$ for 2 hours in each concentration then embedded in epon araldite mixture, the embedded blocks then cut by ultramicrotom in $0.5-1 \mu$ thickness and then ultrathin sections using Leica AG ultramicrotom made with 500 $700 \mathrm{~A}$ thickness and then contrasted in lead citrate and uranyl acetate and examined by JEM 100 CXII electron microscope and photographed by XR- 41 digital camera [33].

Determination of copper residues in dams liver tissue: Digestion of $1 \mathrm{gm}$ of sample with nitric acid and hydrogen peroxide then the total copper content was determined by ICP [34].

Statistical analysis: Data analyzed statically for variance by one way ANOVA and least standard difference LSD according to Snedecor, et al. [35] by computerized SPSS program version 20 .

\section{Results}

\section{Prenatal Maternal Toxicity Upon Exposure to Cu Oxychloride and Chlorfenapyr}

Prenatal maternal clinical signs after cu oxychloride exposure: Pregnant females showed a relative decrease in the feed consumption and the body weight throughout the study in comparison to control especially at the higher dose (1/10 LD50 of cu oxychloride).

$\mathrm{Cu}$ oxychloride treated females showed signs of depression, dullness with melena (black tarry stools) especially at the higher dose (1/10 of LD50) signs illustrated at Figure 1.

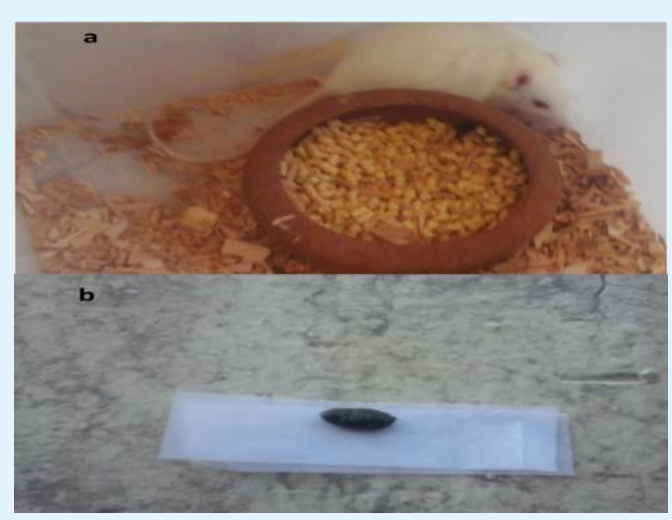

Figure 1: Showing $(a \& b)$ pregnant rats treated with $1 / 10$ LD50 of COC exhibited depression, dullness with melena (black tarry stools).

Maternal body weight gain\% upon exposure to cu oxychloride in pregnant female rats: The results showed a relative significant decrease in body weight gain in all treated groups throughout the study in respect to the control group especially groups of $1 / 10 \mathrm{LD} 50 \mathrm{of} \mathrm{cu}$ oxychloride and results illustrated by Table 2 \& Figure 2.

\begin{tabular}{|c|c|c|c|}
\hline Group & Mean Initial body weight & Mean Final body weight & Body weight gain \% \\
\hline Control & $154.5 \pm 2.18$ & $227.88 \pm 2.49^{\mathrm{a}}$ & 47.5 \\
\hline Group 1/10 LD ${ }_{50}$ of COC & $154.63 \pm 1.92$ & $196.75 \pm 1.7^{\mathrm{b}}$ & 27.24 \\
\hline Group 1/20 LD $\mathrm{D}_{50}$ of COC & $156 \pm 2.38$ & $200.13 \pm 2.03^{\mathrm{bc}}$ & 28.29 \\
\hline
\end{tabular}

Table 2: Showing initial and final body weight mean and body weight gain $\%$ in pregnant female rats administered orally different doses of cu oxychloride (mean $\pm \mathrm{SE}$ ). 


\section{International Journal of Zoology and Animal Biology}

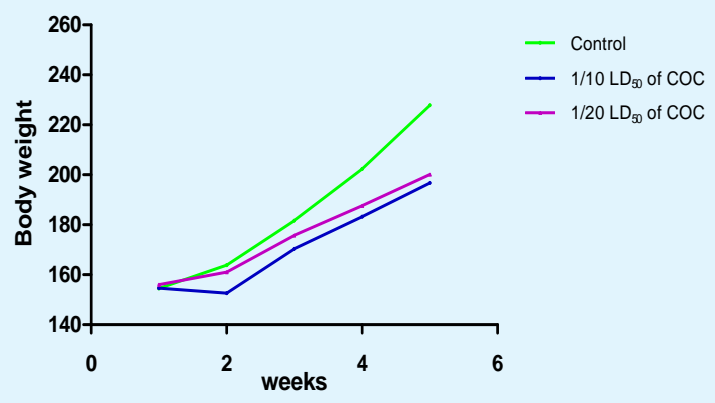

Figure 2: showing body weight mean per weeks after administration of different doses of COC $11 / 10$ LD50 and $1 / 20 \mathrm{LD}_{50}$ of COC equivalent to $147 \mathrm{mg} / \mathrm{kg} \mathrm{Bw}$. and $73.5 \mathrm{mg} / \mathrm{kg}$ Bw. respectively) orally from 6th 15 th days of pregnancy daily in comparison to the control group.

\section{Prenatal maternal Biochemical analysis}

a. Metabolic, liver and kidney functions biomarkers

Estimation of Glucose, cholesterol, total protein, albumin, globulin, ALT, AST, GGT, urea and creatinine had been carried on after administration of different doses of COC (1/10 LD50 and 1/20 LD50 of COC equivalent to 147 $\mathrm{mg} / \mathrm{kg} \mathrm{Bw}$. and $73.5 \mathrm{mg} / \mathrm{kg}$ Bw. respectively) orally from 6th - 15th days of pregnancy daily in comparison to control group Table 3 .

For metabolic biochemical parameters there was a significant decrease of all metabolic biochemical parameters (Glucose, cholesterol, total protein, albumin and globulin) in all treated groups in comparison to the control group where there was a significant decrease in glucose, cholesterol, total protein, albumin and globulin in all treated groups in respect to the control group especially at dose level $1 / 10$ LD50 of COC equivalent to 147 mg/kg Bw Table 3.

For liver function biomarkers there was a significant increase of all biomarkers (ALT, AST and GGT) in all treated groups in comparison to the control group where there was a significant increase in ALT, AST and GGT in all treated groups in respect to the control group especially at dose level 1/10 LD50 of COC equivalent to $147 \mathrm{mg} / \mathrm{kg}$ Bw.

For kidney function biomarkers there was a significant increase in blood urea nitrogen and creatinine in all treated groups in comparison to the control group especially at dose level $1 / 10$ LD50 of COC equivalent to $147 \mathrm{mg} / \mathrm{kg}$ Bw Table 3.

\begin{tabular}{|c|c|c|c|c|c|c|c|c|c|c|}
\hline & ALT (U/I) & AST (U/I) & GGT (U/I) & $\begin{array}{l}\text { Glucose } \\
\text { (mg/dl) }\end{array}$ & $\begin{array}{c}\text { Cholesterol } \\
\text { (mg/dl) }\end{array}$ & $\begin{array}{c}\text { Protein } \\
\text { (g/dl) }\end{array}$ & \begin{tabular}{|c|} 
Albumin \\
(g/dl)
\end{tabular} & $\begin{array}{l}\text { Globulin } \\
\text { (g/dl) }\end{array}$ & $\begin{array}{c}\text { Urea } \\
\text { (mg/dl) }\end{array}$ & $\begin{array}{c}\text { Creatinine } \\
\text { (mg/dl) }\end{array}$ \\
\hline Control & $21.4 \pm 0.55^{\mathrm{e}}$ & $32.0 \pm 0.98^{\mathrm{d}}$ & $17.43 \pm 0.55$ & $143.8 \pm 0.83^{a}$ & $99.23 \pm 1.41^{\mathrm{a}}$ & $8.6 \pm 0.15^{\mathrm{a}}$ & $5.37 \pm 0.12^{\mathrm{a}}$ & $3.23 \pm 0.03^{\mathrm{a}}$ & $34.4 \pm 0.83^{\mathrm{d}}$ & $0.43 \pm 0.01 \mathrm{e}$ \\
\hline $1 / 10 \mathrm{LD}_{50}$ of $\mathrm{COC}$ & $44.03 \pm 0.93^{b}$ & $62.63 \pm 1.16^{b}$ & $42.63 \pm 1.45$ & $83.33 \pm 1.48^{\mathrm{d}}$ & $55.66 \pm 0.91^{\mathrm{c}}$ & $4.3 \pm 0.06^{c}$ & $2.57 \pm 0.15^{\mathrm{d}}$ & $1.73 \pm 0.20^{\mathrm{b}}$ & $66.33 \pm 1.2^{\mathrm{b}}$ & $1.33 \pm 0.09 \mathrm{c}$ \\
\hline $1 / 20 \mathrm{LD}_{50}$ of $\mathrm{COC}$ & $33.3 \pm 1.13^{\mathrm{d}}$ & $46.70 \pm 0.87^{c}$ & $31.7 \pm 1.17^{b}$ & $122.43 \pm 0.91^{c}$ & 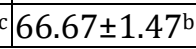 & $6.5 \pm 0.17^{b}$ & $4.43 \pm 0.12^{b}$ & $2.07 \pm 0.07 \mathrm{~b}$ & $44.32 \pm 1.4$ & $.03^{\mathrm{d}}$ \\
\hline
\end{tabular}

Table 3: showed the biochemical metabolic, liver and kidney biomarkers changes after administration of different doses of COC orally from 6th - 15th days of pregnancy daily in comparison to control group.

\section{b. $\quad$ Oxidative stress biomarkers:}

Estimation of GSH, GST, SOD, CAT and MDA had been carried on after administration of different doses of COC (1/10 LD50 and 1/20 LD50 of COC equivalent to 147 $\mathrm{mg} / \mathrm{kg} \mathrm{Bw}$. and $73.5 \mathrm{mg} / \mathrm{kg}$ Bw. respectively) orally from 6th - 15th days of pregnancy daily in comparison to control group and results showed that:
There was a significant decrease in GSH, GST, SOD and CAT in all treated groups when compared with the control groups especially the dose level 1/10 LD50 of COC equivalent to $147 \mathrm{mg} / \mathrm{kg} \mathrm{Bw}$, On the other side MDA showed a significant increase in all treated groups in respect to the control group especially the dose level of 1/10 LD50 of COC equivalent to $147 \mathrm{mg} / \mathrm{kg} \mathrm{Bw}$ Table 4.

\begin{tabular}{|c|c|c|c|c|c|}
\hline \multirow{2}{*}{ Groups } & GSH & GST & SOD & CAT & MDA \\
\cline { 2 - 6 } & mg/g. tissue & U/g. tissue & U/g. tissue & U/g. tissue & nmol/g. tissue \\
\hline Control & $25.99 \pm 1.18 \mathrm{a}$ & $9.19 \pm 0.92 \mathrm{a}$ & $23.51 \pm 1.36 \mathrm{a}$ & $15.88 \pm 1.10 \mathrm{a}$ & $34.70 \pm 1.17 \mathrm{e}$ \\
\hline $\mathbf{1 / 1 0 ~ L D ~}_{\mathbf{5 0}}$ of COC & $16.87 \pm 1.09 \mathrm{c}$ & $3.95 \pm 0.55 \mathrm{c}$ & $14.15 \pm 1.49 \mathrm{bc}$ & $10.39 \pm 0.77 \mathrm{bc}$ & $68.77 \pm 2.54 \mathrm{a}$ \\
\hline $\mathbf{1}_{\mathbf{1} 20} \mathbf{L D}_{\mathbf{5 0}}$ of COC & $20.94 \pm 1.83 \mathrm{~b}$ & $7.21 \pm 0.70 \mathrm{ab}$ & $17.42 \pm 2.30 \mathrm{bc}$ & $13.27 \pm 1.09 \mathrm{ab}$ & $49.74 \pm 1.74 \mathrm{c}$ \\
\hline
\end{tabular}

Table 4: showed the biochemical oxidative stress biomarkers changes after administration of different doses of COC orally from 6 th - 15th days of pregnancy daily in comparison to control group. 
Hematological Finding: The results showed that there was a significant decrease in the total RBCs and $\mathrm{Hb}$ content count in the groups treated with 1/10 LD50 and $1 / 20 \mathrm{LD} 50$ of COC equivalent to $147 \mathrm{mg} / \mathrm{kg} \mathrm{Bw}$. and 73.5 $\mathrm{mg} / \mathrm{kg}$ Bw. respectively, on the other hand total leukocytic count showed a significant increase in the groups treated with $1 / 10$ LD50 and $1 / 20$ LD50 of COC equivalent to $147 \mathrm{mg} / \mathrm{kg} \mathrm{Bw}$. and $73.5 \mathrm{mg} / \mathrm{kg} \mathrm{Bw}$, furthermore there was no significance change in PCV, $\mathrm{MCV}, \mathrm{MCH}$ and MCHC levels in respect to the control values Table 5 .

\begin{tabular}{|c|c|c|c|c|c|c|c|}
\hline & $\begin{array}{c}\text { RBCs (million } \\
\text { cells/uL) }\end{array}$ & Hb (g/dL) & PCV (\%) & MCV (fL) & MCH (pg) & MCHC (g/dL) & $\begin{array}{c}\text { TOTAL WBCs } \\
\text { (1000 cells/uL) }\end{array}$ \\
\hline Control & $8.12 \pm 0.05 \mathrm{a}$ & $14.55 \pm 0.05 \mathrm{a}$ & $45.78 \pm 0.07 \mathrm{a}$ & $56.37 \pm 0.46$ & $17.92 \pm 0.17$ & $31.79 \pm 0.12$ & $7.13 \pm 0.05 \mathrm{~d}$ \\
\hline $\mathbf{1 / 1 0}$ of LD 50 cu & $6.30 \pm 0.11 \mathrm{~d}$ & $11.15 \pm 0.22 \mathrm{~d}$ & $36.07 \pm 0.31 \mathrm{c}$ & $57.24 \pm 0.61$ & $17.68 \pm 0.21$ & $30.90 \pm 0.36$ & $8.57 \pm 0.06 \mathrm{~b}$ \\
\hline $\mathbf{1 / 2 0}$ of LD 50 cu & $7.57 \pm 0.02 \mathrm{~b}$ & $13.05 \pm 0.1 \mathrm{c}$ & $42.68 \pm 0.19 \mathrm{~b}$ & $56.38 \pm 0.32$ & $17.24 \pm 0.15$ & $30.58 \pm 0.29$ & $7.68 \pm 0.18 \mathrm{c}$ \\
\hline
\end{tabular}

Table 5: Showed the hematological finding after administration of different doses of COC orally from 6th - 15th days of pregnancy daily in comparison to control group.

Histopathological findings: The histopathological changes was observed after administration of different doses of COC (147 mg/kg Bw. and $73.5 \mathrm{mg} / \mathrm{kg} \mathrm{Bw.)} \mathrm{orally}$ from 6th - 15th days of pregnancy daily in comparison to the control group and the results showed that there was a clear pathological changes especially at the higher dose level group.

\section{a. Liver}

Dams treated with different doses of COC showed marked degenerative changes and necrosis of the hepatocytes in a dose dependent manner, results illustrated in Figures $3 a$ \& b.

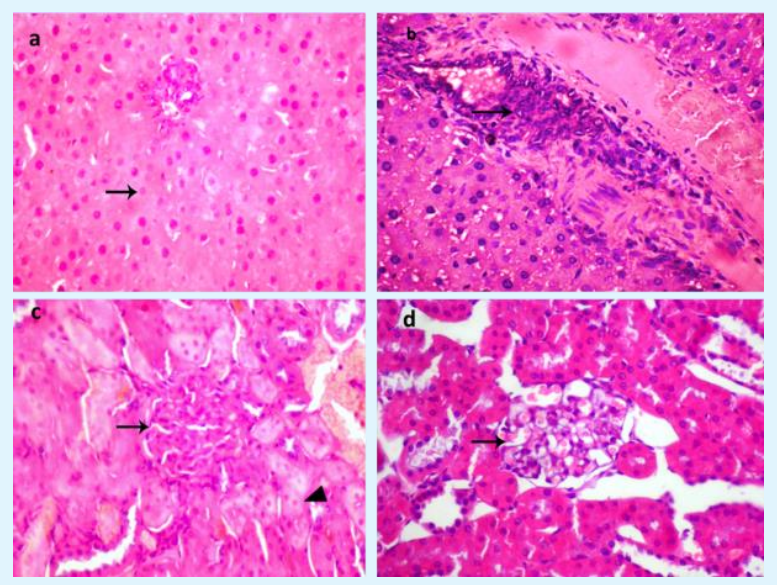

Figure 3: a: Liver of pregnant rat administered orally 1/10 of LD50 of COC from 6th - 15th days of pregnancy daily is showing marked degenerative changes of the hepatocytes and necrosis (arrow). (HE, 400x). b: Liver of pregnant rat administered orally $1 / 20$ of LD50 of COC from 6th - 15th days of pregnancy daily is showing is degeneration of the hepatocytes (arrow). (HE, 400x). c: Kidney of pregnant rat administered orally 1/10 of LD50 of COC from 6th - 15th days of pregnancy daily is showing proliferation of renal glomeruli (arrow) and degenerative changes in renal tubular epithelium (arrow head). (HE, 400x) and d: Kidney of pregnant rat administered orally 1/20 of LD50 of COC from 6th - 15th days of pregnancy daily is showing congestion of renal glomeruli (arrow) (HE, 400x).

\section{b. Kidney}

Dams treated with different doses of COC showed proliferation of renal glomeruli with degenerative changes in renal tubular epithelium besides congestion of renal glomeruli in a dose dependent manner, results illustrated in figures $3 c \& d$.

\section{c.Brain}

Dams treated with 1/10 COC showed showing astrocytosis and microgliosis, results illustrated in Figure 4. 


\section{International Journal of Zoology and Animal Biology}

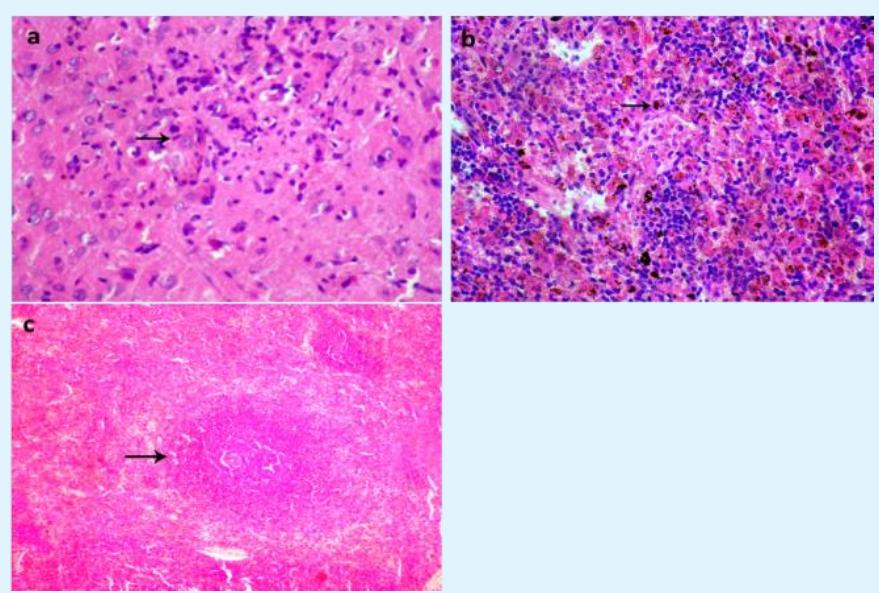

Figure 4: a: Brain of pregnant rat administered orally 1/10 of LD50 of COC from 6th - 15th days of pregnancy daily is showing astrocytosis and microgliosis (arrow). (HE, 400x). b: Spleen of pregnant rat administered orally 1/10 of LD50 of COC from 6th - 15th days of pregnancy daily is showing marked hemosiderosis (arrow) and lymphoid depletion. (HE, 100) and c: Spleen of pregnant rat administered orally 1/20 of LD50 of COC from 6th - 15th days of pregnancy daily is showing lymphoid depletion (arrow). (HE, 400x).

\section{d. Spleen}

Dams treated with different doses of COC showed necrosis of lymphoid tissue in white pulp besides lymphoid depletion in a dose dependent manner, results illustrated in Figure 4.

\section{Transmission electron microscope examination:}

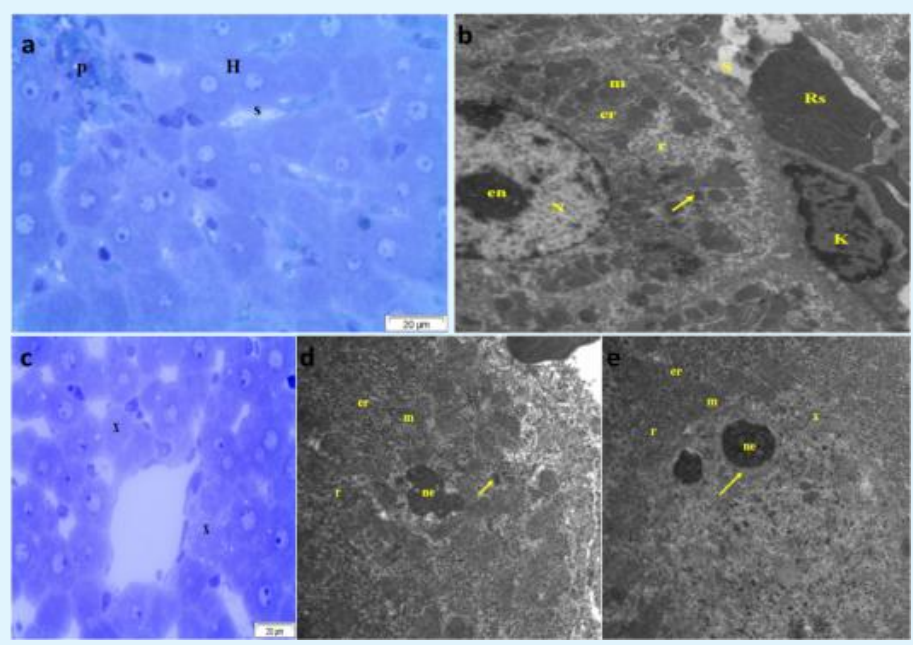

Figure 5: a: Light micrograph of hepatic tissue of control dam showing the hepatic cell arranged in plats (H) with vesicular nucleus and prominent nucleolus, sinusoids (s) and portal area (P) contain the portal vessels with normal morphological appearance. T.B. Stain.

b: T.E. micrograph of hepatic tissue displaying the hepatic sinusoid (S) contain RBCs (Rc) and kupffer cell (K) having nucleus and cytoplasm and contain mitochondria and lysosomes. The hepatic cell having large vesicular nucleus (N) contain prominent nucleolus (en) and cytoplasm contain cell organelles such as RER (er), mitochondria (m) microbodies (arrow) and few ribosomes (r)

c: Light micrograph of hepatic tissue of pregnant rat administered orally 1/10 LD50 of COC from 6th - 15th days of pregnancy daily showing the absence of the nucleus in some hepatocytes $(x)$ and others contain two nucleuses (arrow). 
d: T.B. Stain. T.E. micrograph of hepatocytes of pregnant rat administered orally 1/10 LD50 of COC from 6th - 15th days of pregnancy daily showing absence of the nucleus and only the nucleolus (ne) present without other construction of the nucleus, the cytoplasmic organelles not separated from the nuclear materials and showing swollen mitochondria (m) and RER (er) with large number of microbodies (arrow) and free ribosomes (r).

e: T.E. micrograph of hepatic cells of pregnant rat administered orally 1/20 of LD50 of COC from 6th - 15th days of pregnancy daily displaying nuclear membrane discontinuity and the chromatin clump appeared electron lucent (x). The nucleus ( $\mathrm{N}$ displaying homogenous electron lucent areas (arrow) surrounded two nucleoli (ne) and even throughout the nucleus, the cell organelles as mitochondria (m) and RER (er) showing swelling besides increase in the free ribosomes (r).

\section{Determination of Copper residues in the dams liver tissue:}

Linearity: A standard calibration curve of copper constructed by plotting the analyte concentration against the peak areas. At $324 \mathrm{~nm}$, the standard curve equation was $\mathrm{Y}=219091.485 \mathrm{X}-30.159$ and correlation coefficient $\mathrm{R} 2=0.9999$, $\mathrm{y}$ is the peak area and $\mathrm{x}$ is the concentration (ppm). The Linearity correlation is shown in Figure 6.

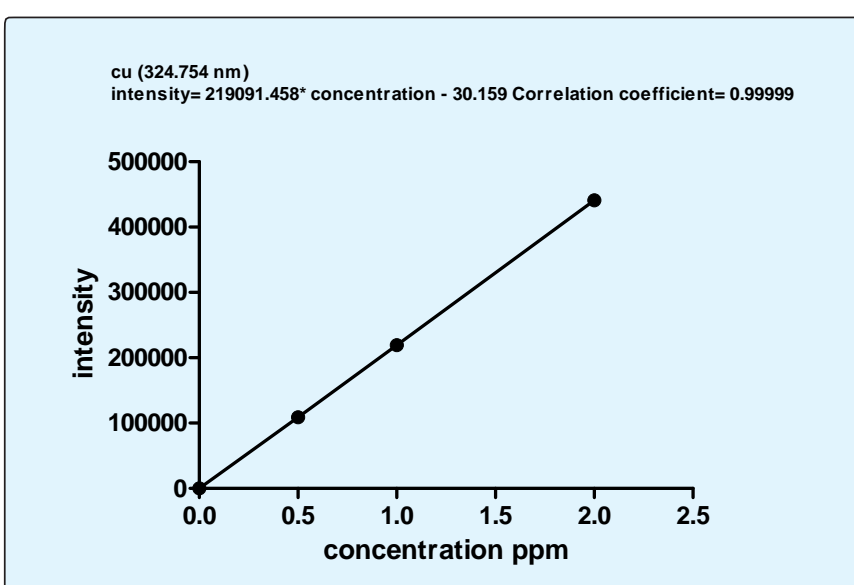

Figure 6: showed the Linearity correlation for copper calibration curve.

\section{Copper residues in the liver tissue:}

The results showed that the level of copper residues in the liver tissue significantly increased after administration of different doses of COC $11 / 10$ LD50 and $1 / 20 \mathrm{LD} 50$ of COC equivalent to $147 \mathrm{mg} / \mathrm{kg} \mathrm{Bw}$. and 73.5 $\mathrm{mg} / \mathrm{kg} \mathrm{Bw}$. respectively) orally from 6th - 15th days of pregnancy daily in comparison to control group and the results showed in Table 6.

\begin{tabular}{|c|c|}
\hline Group & Copper level $(\boldsymbol{\mu g} / \mathbf{g}$ tissue) \\
\hline Control & $0.059 \pm 0.001^{\mathrm{c}}$ \\
\hline $1 / 10$ of LD $50 \mathrm{cu}$ & $0.102 \pm 0.002^{\mathrm{b}}$ \\
\hline $1 / 20$ of LD $50 \mathrm{cu}$ & $0.2073 \pm 0.007^{\mathrm{a}}$ \\
\hline
\end{tabular}

Table 6: showed the level of copper residues in the liver tissue of treated dams with different doses of COC.

\section{Discussion}

The widespread application of pesticides in the agricultural programs causes serious health hazards and environmental pollution and with the introduction of new pesticides that may be more toxic necessitates recognition of their hazards to the population health and ecosystem diversity. Whereas the toxicity mechanism of most pesticides through free radical production and antioxidants alteration that play a crucial role in induction of oxidative stress and cellular oxidative damage [36].

All treated dams with different doses of COC (147 and $73.5 \mathrm{mg} / \mathrm{kg} \mathrm{Bw}$. COC) throughout the study showed a significant relative decrease in the body weight in a dose dependent manner in respect to the control group as the exposure to excess copper in diet for 9 weeks significantly decrease the final body weights in rats[37]. Also, cu toxicity in rat model administered orally 100 and $200 \mathrm{mg} / \mathrm{kg}$ daily for 90 days significantly decrease the body weight when compared to the control and such decrease in the body weight may be due to liver damage as it considered as the major target organ in cupper oxychloride toxicity [38]. Addationlly, decrease in food consumption might be responsible for such decrease [39].

Most metabolic biochemical parameters as glucose, cholesterol, total protein, albumin and globulin in a dose dependent manner were affected by test compound treatment in respect to the control group as the toxic effect of copper in Cyprinus carpio for 30 days that resulted in a significant decrease in the level of glucose, total protein and cholesterol [40]. Also, the copper toxicity in Mugil seheli fish at dose level 5.36 and 1.64 ppm and the result showed a significant decrease in the glucose, lipid, glycogen and total protein [41]. Metabolic disorders after exposure to COC may be explained in the light of due to copper is a vital trace element to all living organisms as it participates in various metabolic processes but excess of copper has deleterious effect in organisms and impair the metabolic activity as it stimulates free radical production and lipid peroxidation 


\section{International Journal of Zoology and Animal Biology}

in the living cell and disturbs the whole body antioxidant capacity [42].

Hepatorenal toxic effects of COC evidenced by increase of ALT, GGT, AST, Urea and Creatinine as the hepatotoxicity of COC in rats in a toxicological study at dose level 500, 1000 and $2000 \mathrm{mg} / \mathrm{kg} \mathrm{Bw}$. for 90 days (10) and also, COC may harm human and public health causing hepatotoxicity with a significant increase in ALT and AST also according to [43]. Liver considered as the primary target organ in copper toxicity as liver involved in the process of copper homeostasis, synthesis and storing of copper-containing protein ceruloplasmin so many animals can cope with excess copper exposure by liver but overwhelming of such mechanism may occur with repeated exposure resulting in hepatotoxicity also Copper nephrotoxicity and renal dysfunction reported through multiple studies after prolonged exposure to copper as copper accumulated in the proximal renal tubules causing a dose dependent increase in the renal serum creatinine and urea levels and decrease in protein level due to proteinuria and liver damage [44].

For explain the toxicity of $\mathrm{COC}$ by modulation of oxidative stress biomarkers, all treated dams with different doses of COC (147 and $73.5 \mathrm{mg} / \mathrm{kg} \mathrm{Bw}$. COC) throughout the study showed a dose dependent decrease in GSH, GST, SOD and CAT and increase in MDA after exposure to COC in a dose dependent manner in respect to the control group. Inconsistent with exposure of rats to COC at dose level 500, 1000 and $2000 \mathrm{mg} / \mathrm{kg} \mathrm{Bw}$. for 90 days caused a marked increase in the liver MDA due to lipid peroxidation [10]. On the other hand liver GSH seemed to be not affected by COC and according to [42]. Excess of copper oxychloride has deleterious effect in organisms as it stimulates free radical production in the living cell through Fenton reaction with lipid peroxidation and disturbs the whole body antioxidant capacity.

Hematological effects of COC ensured by significant decrease in RBCs count, Hb content and PCV and on the other hand a significant increase in total leukocytic count after exposure to COC in a dose dependent manner. As the copper oxychloride may accumulate in various tissues as a heavy metal and cause hemolytic anemia [3]. Also the copper harbor compounds may promote hemolytic anemia and hemorrhage with abnormal high blood $\mathrm{Cu}+$ levels [45]. Furthermore Chung, et al. revealed that the copper caused a significant decrease in the whole Hematological parameters as hemoglobin and red blood cell on the other hand there was a sever increase in the white blood cell.
Histopathological and Ultrastructural alteration of COC (147 and $73.5 \mathrm{mg} / \mathrm{kg} \mathrm{Bw.} \mathrm{COC)} \mathrm{revealed} \mathrm{by} \mathrm{a} \mathrm{sever}$ histopathological changes in the liver, kidney, spleen and brain also a significant morphological changes in the hepatocytes with ultrastructural degenerative changes after exposure to COC in a dose dependent manner in respect to the control group. Ssuch results confirmed with the biochemical changes in the treated dams also according to Sevcikova, et al. [8] liver considered as the target organ in copper oxychloride toxicity and play a crucial role in copper balance homeostasis so excess copper compromise the liver threshold causing severe pathological lesions, degenerations, swollen nuclei and mitochondria. Moreover, the hepatocellular injuries in rats through accumulation of copper in nucleus but not in lysosomes as previously thought that cupper causing nuclear irreversible damage that may be responsible for cell death of hepatocytes in the whole liver [39].

Copper residues level in the liver tissue were proofed as all treated dams with different doses of COC (147 and $73.5 \mathrm{mg} / \mathrm{kg}$ Bw. COC) throughout the study showed a significant increase in the level of copper residues in the liver tissues in a dose dependent manner in comparison to control. Similarly, the COC may accumulate in various tissues and causing hepatic and renal dysfunction with cellular degeneration [3]. Also the copper retention in the hepatic tissues may occur due to impairment of the excretory mechanism whereas the normal level of copper maintained through the copper excretory mechanism in bile and the free copper bound to ceruloplasmin but when such mechanisms overwhelmed with excess copper it accumulates in tissues causing toxicity.

On conclusion, COC may accumulate in various tissues causing hepatic and renal toxicity with evidence of cellular degeneration and should use as fungicide according restricted precautions.

\section{References}

1. Stanic S (2008) Genotoxic effects of fungicide Copper oxychloride on Drosophila melanogaster. Periodicum biologorum 110(4): 347-349.

2. Fishel FM (2005) Pesticide toxicity profile: Copperbased pesticides. UF/IFAS Extension. pp: 1-4.

3. Waheed S, Kamal A, Malik RN (2013) Human health risk from organ-specific accumulation of toxic metals and response of antioxidants in edible fish species from Chenab River, Pakistan. Environ Sci Pollut Res Int 21(6): 4409-4417. 


\section{International Journal of Zoology and Animal Biology}

4. Osman AH, El Shama SS, Osman, AS, Elhameed AKA (2011) Toxicological and pathological evaluation of prolonged bromuconazole fungicide exposure in male rats. Med J Cairo Univ 79(10): 555-564.

5. Helling B, Reinecke SA, Reinecke AJ (2000) Effects of the fungicide copper oxychloride on the growth and reproduction of Eisenia fetida (Oligochaeta). Ecotoxicology and environmental safety 46(1): 108116.

6. Snyman RG, Reinecke SA, Reinecke AJ (2000) Hemocytic lysosome response in the snail Helix aspersa after exposure to the fungicide copper oxychloride. Archives of environmental contamination and toxicology 39(4): 480-485.

7. Nalbur BE, Eleren SC, Şahin S, Alkan U (2012) Toxic Effects of Copper-Based and Synthetic Organic Pesticides on Activated Sludge. CLEAN-Soil, Air, Water, 40(1): 39-44.

8. Sevcikova M, Modra H, Blahova J, Dobsikova R, Plhalova L, et al. (2016) Biochemical, haematological and oxidative stress responses of common carp (Cyprinus carpio L.) after sub-chronic exposure to copper. Veterinární Medicína, 61(1): 35-50.

9. Chung MK, Baek SS, Lee SH, Kim H, ChoiK, et al. (2009) Combined repeated dose and reproductive/developmental toxicities of copper monochloride in rats. Environ Toxicol 24(4): 315326.

10. El Hak HNG, Mobarak YM (2018) The ameliorative impacts of curcumin on copper oxychloride-induced hepatotoxicity in rats. The Journal of Basic and Applied Zoology 79(1): 44.

11. Hutanu D (2012) The effect of copper chloride upon the follicles stage in mouse ovaries. Annals of the Romanian Society for Cell Biology 17(1): 1-6.

12. Lushchak VI (2011) Environmentally induced oxidative stress in aquatic animals. Aquatic toxicology, 101(1): 13-30

13. Fuentealba I, Haywood S, Foster J (1989) Cellular mechanisms of toxicity and tolerance in the copperloaded rat: II. Pathogenesis of copper toxicity in the liver. Experimental and molecular pathology 50(1): 26-37.

14. Bakre DS, Kaliwal BB (2017) In-vitro Assessment of Carbendazim and Copper oxychloride cytotoxicity on
HaCaT and HepG2 human cell lines. Journal of Applied Biology \& Biotechnology 5(3): 23-29.

15. Bruce RD (1985) An Up-and-Down Procedure for Acute Toxicity Testing. Fundam Appl Tox 5(1): 151157.

16. Organisation for Economic Co-operation and Development OECD (2001) Acute Oral Toxicity (OECD Test Guideline 425) Statistical Programme (AOT 425 StatPgm), Version: 1.0.

17. Bhardwa Sj, Srivastava MK, Kapoor U, Srivastava LP (2010) A 90 days oral toxicity of imidacloprid in female rats: Morphological, biochemical and histopathological evaluations: Food Chem Toxicol 48(5): 1185-1190.

18. Fernandez Botran R, Gorantla V, Sun X, Ren X, PerezAbadia G, et al. (2002) Targeting of glycosaminoglycan-cytokine interactions as anovel therapeutic approach in allotransplantation1.Transplantation 74(5): 623-629.

19. Agbasi PU, Abasi N, Onye JJ, Ibeawuchi C, Uzoechi SC, et al. (2015) The effect of sub chronic low dose of DDVP and sodium azid on the hematological indices of albino rats, toxicology physiology and biochemistry 4: $103-110$.

20. Burtis CA, Ashwood ER (1999) Tietz textbook of clinical chemistry. $3^{\text {rd }}$ (Edn.), pp: 29-150.

21. Young DS (1990) Effect of drugs on clinical laboratory tests. $3^{\text {rd }}$ (Edn.), AACC, Philadelphia 3: 6-12.

22. Kaplan LA (1984) A colorimetric method for determination of glucose, Clin Chem the C.V. Mosby CO. St Louis. Toronto. Princeton pp: 1032-1036.

23. Tietz N W (1999) A colorimetric method for detection of protein, Text book of clinical biochemistry $3^{\text {rd }}$ (Edn.), C.A pp: 577-530.

24. Webster D (1974) A colorimetric method for detection of albumin, Clin Chem. Acta 53: 109-115.

25. Young DS (1990) A colorimetric method for detection of creatinine, effect of drugs on clinical laboratory tests. $3^{\text {rd }}$ (Edn.), 3: 6-12.

26. Tabacco A (1979) A colorimetric method for detection of urea. Cin Chem 25: 336-337. 


\section{International Journal of Zoology and Animal Biology}

27. Naito HK, Kaplan A (1984) A colorimetric method for determination of Cholesterol. Clin Chem the C.V. Mosby CO. St Louis, Toronto, Princeton, pp: 119411206 and 437.

28. Beutler E (1963) Improved method for the determination of blood glutathione. J lab clin Med 61: 882-888.

29. Nishikimi M, Roa NA, Yogik (1972) A colorimetric method for determination of serum Soperoxide dismutase. Biochem Bioph Res Common 46: 849-854.

30. Goth L (1991) A simple method for determination of serum catalase activity and revision of reference range. Clinica chimica acta 196(2-3): 143-151.

31. Satoh K (1978) Serum lipid peroxide in cerebrospinal disorder determined by a new colorimetric method. Clinica Chemical Acta 90(1): 37-43.

32. Bancroft JD, Stevens A (1990) Theory and practice of histological techniques.

33. Bozzola J, Russell L (1991) Electron microseopy principles and techniques for biologists. Jones and Bartlitt publishers, 20 park plasa Boston Ma o 2116, USA.

34. Cerchiaro G, Manieri TM, Bertuchi FR (2013) Analytical methods for copper, zinc and iron quantification in mammalian cells. Metallomics, 5(10): 1336-1345.

35. Snedecor GW, Cochran WG (1989) Statistical Methods, eight editions. Iowa state University press, Ames, Iowa.

36. Abdollahi M, Ranjbar A, Shadnia S, Nikfar S, Rezaiee A (2004) Pesticides and oxidative stress: a review. Medical Science Monitor 10(6): RA141-RA147.

37. Dillard CJ, Tappel AL (1984) Lipid peroxidation and copper toxicity in rats. Drug and chemical toxicology, 7(5): 477-487.
38. Kumar V, Kalita J, Misra UK, Bora HK (2015) A study of dose response and organ susceptibility of copper toxicity in a rat model. J Trace Elem Med Biol 29: 269274.

39. Fuentealba I, Haywood S, (1988) Cellular mechanisms of toxicity and tolerance in the copper-loaded rat. I. Ultrastructural changes in the liver. Liver 8(6): 372380.

40. Dhanapakiam P, Ramasamy VK (2001) Toxic effects of copper and zinc mixtures on some haematological and biochemical parameters in common carp, Cyprinus carpio (Linn). J environ biol 22(2): 105-111.

41. Abou El-Naga EH, El-Moselhy KM, Hamed MA (2005) Toxicity of cadmium and copper and their effect on some biochemical parameters of marine fish mugil sheheli. 31(2): 60-71.

42. Husak VV (2015) Copper and copper-containing pesticides: metabolism, toxicity and oxidative stress. Journal of Vasyl Stefanyk Precarpathian National University 2 (1): 39-51.

43. Babaei H, Kheirandish R, Ebrahimi L (2012) The effects of copper toxicity on histopathological and morphometrical changes of the rat testes. Asian Pacific Journal of Tropical Biomedicine 2(3): 16151619.

44. Babaknejad N, Moshtaghie AA, Shahanipour K (2015) The Toxicity of Copper on Serum Parameters Related to Renal Functions in Male Wistar Rats. Zahedan Journal of Research Medical Science 15.

45. Shivanandappa T, Krishnakumar, MK, Majumder SK (1983) Testicular atrophy in Gallus domesticus fed acute doses of copper fungicides. Poultry science 62(2): 405-408. 